\title{
Intergranular degradation of stainless steel tubular components used for kerosene transportation. Metallographic analysis
}

\author{
Ion Palamarciuc ${ }^{1,2}$, Dan Gelu Galusca ${ }^{1}$, Monica Ratoi $^{3}$, Brian Mellor ${ }^{3}$, Cătălin Gabriel \\ Dumitraș $^{4}$, and Maricel Agop ${ }^{5, *}$ \\ ${ }^{1}$ Gheorghe Asachi Technical University of Iasi, Faculty of Materials Science and Engineering, Bd. D. \\ Mangeron no. 41, 700050, Iasi, Romania \\ ${ }^{2}$ Alexandru Ioan Cuza University of Iasi, Faculty of Physics, Bd. Carol I, 700506, Iasi, Romania \\ ${ }^{3}$ University of Southampton, Faculty of Engineering and Environment, United Kingdom \\ ${ }^{4}$ Gheorghe Asachi Technical University of Iasi, Faculty of Machine Manufacturing and Industrial \\ Management, Bd. D. Mangeron no. 67, 700050, Iasi, Romania \\ ${ }^{5}$ Gheorghe Asachi Technical University of Iasi, Faculty of Machine Manufacturing and Industrial \\ Management, Department of Physics, Bd. D. Mangeron no. 67, 700050, Iasi, Romania
}

\begin{abstract}
The chemical interactions between the kerosene compounds and the stainless steel structure of the tubular components, through which kerosene is transported, develop a degradation phenomenon, causing intergranular contamination from the surface to the inner part (process based also on mass transport, i.e. diffusion at low temperatures). This is the most dangerous effect of chemical contamination, affecting the active section of the tubular components, which can reach a critical section, leading to catastrophic consequences in the operation of a jet engine. Metallographic analysis of the tubular components of such a jet engine, manufactured from stainless steel $12 \mathrm{H} 18 \mathrm{~N} 10 \mathrm{~T}$, through which kerosene has been transported, come to confirm the intergranular contamination.
\end{abstract}

\section{Introduction}

Fuel system components of turbo engines, as well as lubricating oil systems are subjected to repeated thermal shocks, which hampers their performance and operating time.

Pressure increasing in the fuel system ( 65 .... 90 bar) leads to temperature increase, which favors improvement of combustion efficiency. Also, the temperature of the flue gas increases, temperature restricted by conditions for the safe operation of gas turbines. Cooled gas temperature should not exceed $1198{ }^{\circ} \mathrm{C}$ at turbine entry and 730 ${ }^{\circ} \mathrm{C}$ at the turbine output, not to damage the blades. Also, the oil temperature must not exceed $150{ }^{\circ} \mathrm{C}$ [1-2]. Maintaining the temperature of lubricating oil and flue gas temperature below the maximum permitted levels is achieved using heat exchangers that use kerosene as coolant [3].

\footnotetext{
* Corresponding author: m.agop@yahoo.com
} 
In conditions of high temperature and pressure, kerosene becomes a supercritical fluid is neither gas nor liquid - but has properties of both aggregation states [4]. This kerosene property ensures improved performance of engines, but also produces kerosene oxidation, thermal decomposition (pyrolysis) and the deposits formation [5], processes strongly influenced by temperature, pressure, fuel composition and surface support [6]. The formation of deposits on the fuel system components is inevitable and can have catastrophic consequences [7]. Therefore, the study of the mechanisms that lead to the "generation" and evolution of deposition is very important.

In this paper, such a mechanism, specifically, intergranular contamination is confirmed by metallographic analysis of the tubular components of such a jet engine, manufactured from stainless steel $12 \mathrm{H} 18 \mathrm{~N} 10 \mathrm{~T}$, through which kerosene has been transported. The originality of this research consists in the fact that the samples were collected from a jet engine and the pipes have been used in real conditions, while in literature we can find information based on laboratory operating conditions.

\section{Experimental procedures and results}

\subsection{Samples}

The analyzed pipes have been collected from the fuel system of a jet engine. They were used for transporting TS-1 jet fuel at high pressure (maximum 64 bar) and different temperatures (minimum $-60{ }^{\circ} \mathrm{C}$ and maximum $150{ }^{\circ} \mathrm{C}$ ). The pipes are made from $12 \mathrm{H} 18 \mathrm{~N} 10 \mathrm{~T}$ austenitic stainless steel with the external diameter of $16 \mathrm{~mm}$. On the inner surface of the pipes we could observe carbon depositions and we prepared two types of samples: as received and ultrasonically cleaned in distilled water in order to detach the deposited layer for further analysis.

\subsection{Metallographic analysis}

The microstructure of the samples has been analyzed in cross section and longitudinal section by optical microscopy after metallographic preparation and etching in $10 \%$ oxalic acid. In cross section we could observe minor surface defects (pits), as seen in Figure 1.
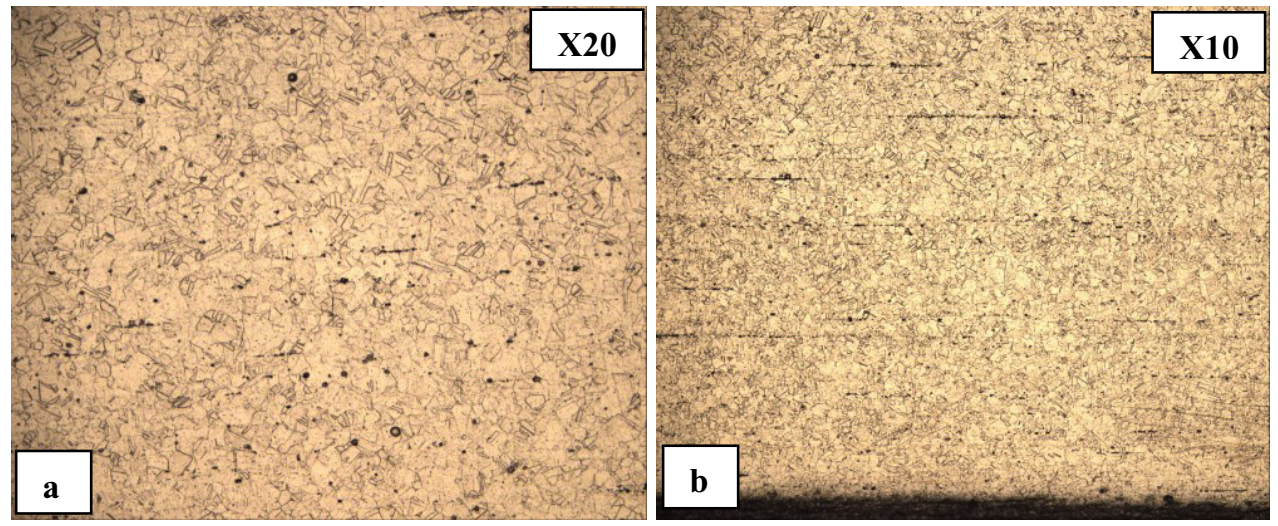

Fig. 1. Microstructure of the steel in cross section: (a) in the middle of the pipe wall, (b) at the external wall 

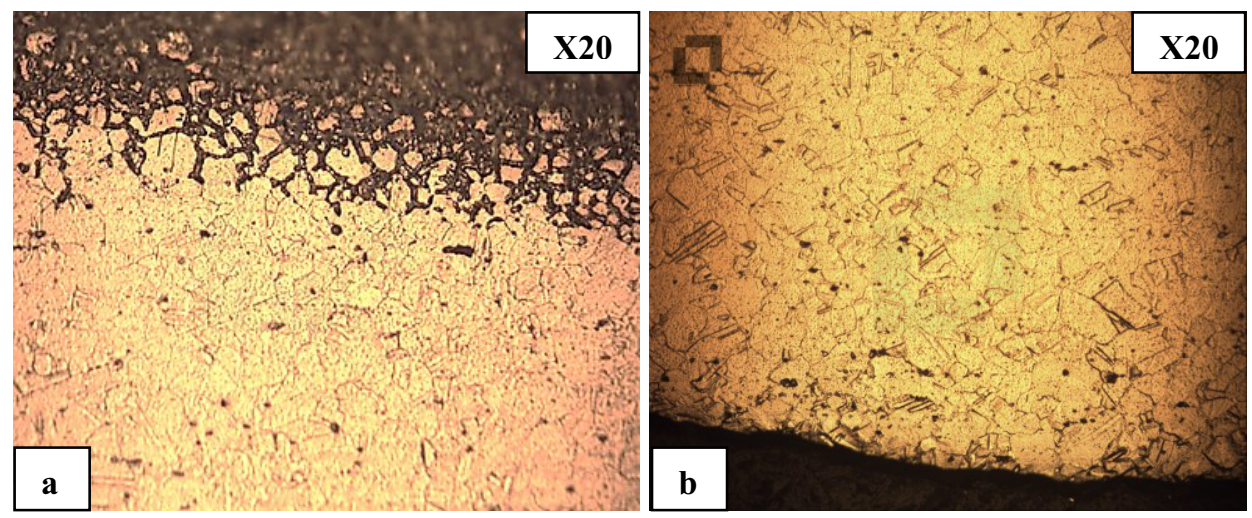

Fig. 2. Microstructure of the steel in longitudinal section: (a) at the internal wall, (b) at the external wall

However, only in longitudinal section, on the internal wall we could observe the intergranular corrosion attack (Figure 2a).

\subsection{D and 2D surface characterization}

The cylindrical geometry of the samples, the non-uniform and dark color of the depositions did not allow us to perform any exact quantitative measurements.

This required the use of focus-variation microscopy techniques, so we characterized the surfaces with an Alicona Infinite Focus G4 microscope and used its IF-Measure Suite 5.1 software for image processing. Figure 3 illustrates the 3D image of the carbon deposition on the steel surface and the defects emerging to the surface.

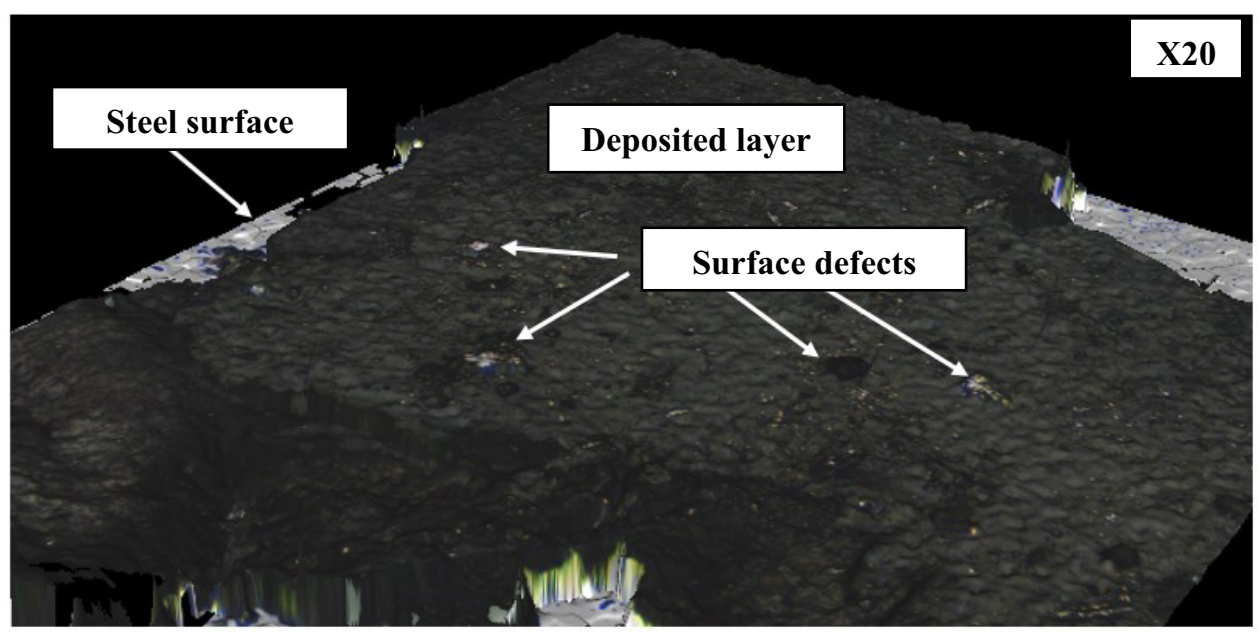

Fig. 3. 3D image of the carbon deposition on the surface of the steel

At higher magnification we detected surface defects such as corrosion pits. After extracting the surface profile along a linear defect (that is parallel to the direction of the fluid flow) we could measure the depth of the defect. It can be seen (Figure 4) that the depth of the defect in the analyzed area is about $3 \mu \mathrm{m}$. 


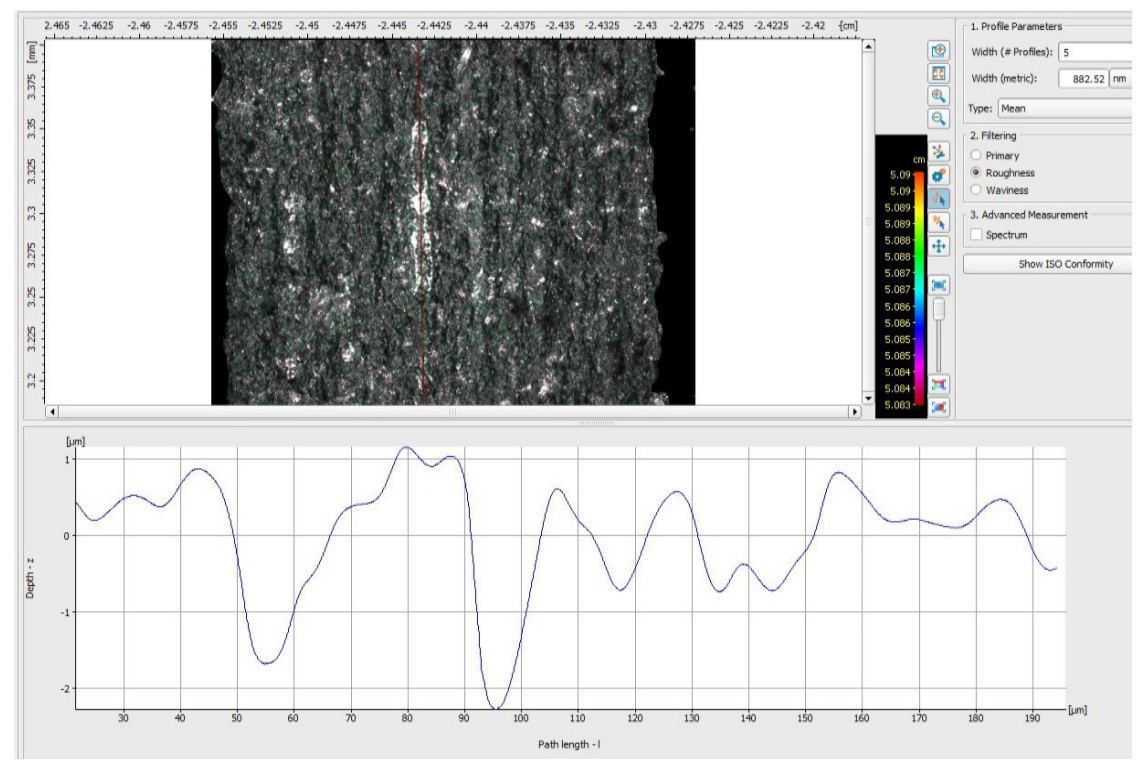

Fig. 4. Surface profile along the defect

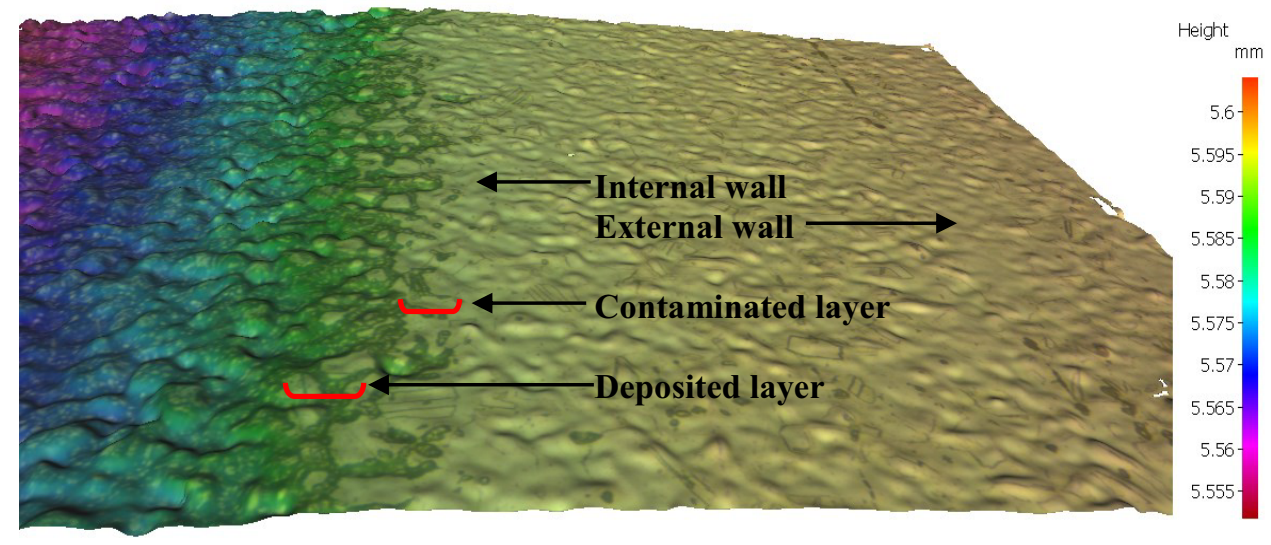

Fig. 5. Surface topography of a longitudinal cross section of a pipe

From Figure 5 it can be seen that two types of interfaces were formed: an interface between the steel and the deposition and another interface between the deposition and the transported fluid. The first one represents a contaminated layer (containing corrosion products), anchored in the microstructure of the steel and the second represents a deposited layer.

The interaction between kerosene components and steel is causing changes in the chemical composition also [8,9] and it is directly correlated with the effects on the mechanical and physical properties. For example, penetration of sulfur into the steel surface, through the grain boundaries is a process that increases the dislocations density (the result of steel embrittlement) and is amplified by the chemical interaction leading to brittle fracture. 


\section{Conclusions}

Our metallographic analysis of the tubular components of such a jet engine, manufactured from stainless steel $12 \mathrm{H} 18 \mathrm{~N} 10 \mathrm{~T}$, through which kerosene has been transported, come to confirm the intergranular contamination.

This is the most dangerous effect of chemical contamination, affecting the active section of the tubular components, which can reach a critical section, leading to catastrophic consequences in the operation of a jet engine. We note that a similar effect occurs in the controlled release of drugs by diffusion complex at low temperatures (critical, subcritical and supercritical) [10-13] and plasma discharge [14-16].

This work was supported by the strategic grant POSDRU/159/1.5/S/ 133652, co-financed by the European Social Fund within the Sectorial Operational Program Human Resources Development $2007-2013$.

\section{References}

1. A. Ersin, A. T. Shih, S. M. Jones, M. S. Reveley, J. T. Luxhøj, J. K. Evans, J. Risk Res. 18, 428 (2015)

2. *** Operating and maintenance manual of the jet engine AI-25 (Moscow, 1980)

3. H. C Mongia, Proceedings of the Turbine Technical Conference and Exposition (2013)

4. I. Gainar, Jet engines (Ars Docendi, Bucuresti, 2000)

5. S. P. Heneghan, S. Zabarnick, Fuel 73, 35 (1994)

6. E. Grant Jones, L.M. Balster, W. J. Balster, Energy Fuels 12, 990 (1998)

7. T. Edwards, W. Harrison, S. Zabarnick, M. DeWitt, C. Bentz, Proceedings of the 40th AIAA/ASME/SAE/ASEE Joint Propulsion Conference and Exhibit, 3886 (2004)

8. I. Palamarciuc, Cercetări privind efectul contaminării cu produse petroliere asupra caracteristicilor fizico-chimice ale oțelurilor utilizate în construcția unor componente tubulare, (Universitatea Tehnica "Gh. Asachi", Iași, 2017).

9. I. Palamarciuc, D. G. Galusca, J. Manhart, N. Okolie, Proceedings of Metal 2015 Conference. Ostrava, Czech (2015)

10. V. A. Paun, M. Popa, J. Desbrieres, C. A. Peptu, S. V. Dragan, G. Zegan, G. Cioca, Mat. Plast. 53, $590(2016)$

11. V. A. Paun, L. Ochiuz, M. Hortolomei, A. Creteanu, I. Stoleriu, C. M. Ghiciuc, G. T. Serban, G. Zegan, G. Cioca, Mat. Plast. 53, 699 (2016)

12. M. Stanciu, I. S. Zaharie, L. G. Beraz, G. Cioca, Acta Endocrinol. 12, 485 (2016)

13. E. S. Băcăiţă, C. Bejinariu, B. Zoltan, C. Peptu, G. Andrei, M. Popa, D. Magop, M. Agop, J. Appl. Math., 653720 (2012)

14. S. Gurlui, M. Agop, M. Strat, G. Strat, S. Băcăiţă, A. Cerepaniuc, Phys. of Plasmas 13, 063503 (2006)

15. M. Agop, D. Alexandroaiei, A. Cerepaniuc, S. Băcăiţă, Chaos Solitons Fractals 30, 470 (2006)

16. S. Gurlui, M. Agop, M. Strat, G. Strat, S. Băcăiță, Jpn. J. Appl. Phys. 44, 3253 (2005) 